\title{
Reviewing the Influences of Teachers' Characteristics on Students' Learning Efficiency During Classroom Interaction
}

\author{
Yi Liu ${ }^{1, a, \dagger, *}$, Jing $\mathrm{Wu}^{2, b, \dagger, *}$ Jing $\mathrm{Zhong}^{3, \mathrm{c}, \dagger, *}$ \\ 1. School of Foreign Languages, Southwest Jiaotong University, Chengdu, Sichuan Province, 611756, China \\ 2. School of Social Science, University of California, Irvine, California, United States \\ 3. Zhuhai College of Science and Technology, Zhuhai, Guangdong Province, 519041, China \\ *Corresponding author.Email: ${ }^{a}$ Niki_YiLiu@126.com, ${ }^{b}$ jwu26@uci.edu, ${ }^{c}$ zoey552021@163.com
}

These authors contributed equally.

\begin{abstract}
This article is a literature review of the teacher's characteristics that affect classroom interaction. It explores the topic from three different aspects: verbal feedback, body gesture, and some other factors. Firstly, since teachers' oral feedback boosts students' performance in classroom interaction, teachers have to notice its significance during the pedagogical process and understand the four main feedback comments involved in the article. In addition, a gesture of teachers improves the efficiency of classroom interactions, which can deepen students' comprehension of course content and potentially ensure the accuracy of what they learn. In addition, other characteristics included teachers' attire and gender that can enhance classroom interactions by applying various impacts to the teaching approaches and understanding student's acceptance of the teacher. As classroom interaction is the process that promotes the mutual understanding between teachers and students, it allows teachers to know whether students can grasp the key ideas and connect with students closer. Hence, classroom interaction plays an important role and should not be ignored in the education area. This article discusses what teachers' characteristics impact classroom interactions and probably inspires future teachers and researchers.
\end{abstract}

Keywords: Teachers' Characteristics, Students' Learning Efficiency, Classroom Interactions, Feedback, Gesture, Other Characteristics, Attire, Gender

\section{INTRODUCTION}

Teachers' characteristics, including verbal feedback, gestures, teachers' dressing styles, and gender, play a crucial role in classroom interaction. Students are exposed to a variety of teachers and teaching styles. Every teacher has different characteristics but with the same objective: the transfer of knowledge and skills. A reasonable hypothesis might be that students will give higher ratings to a teacher from whom they believe they learned more. Students might have various responses to teachers' characteristics. Specifically, students are disposed to have higher learning efficiency and stand a greater possibility of yielding positive results if the teachers' characteristic is compatible with their learning style. In the following section, several aspects pertaining to teachers' characteristics are discussed. This paper mainly involves how different tasks and the level of students' esteem affect the quality of verbal feedback. Then, it centers on how the use of gestures can promote students' understandings of knowledge. Finally, it discusses other potential characteristics that subconsciously exert impacts on student' learning

\section{TEACHER FEEDBACK}

This section reviews the characteristic of teachers' verbal feedback. In the context of classroom discourse, various definitions of the term feedback have been proposed. Most of these definitions indicate that feedback refers to giving evaluations to students' work. More specifically, this form of interaction shows learners their errors and guides them to correct their work $[1,2]$. Thus, verbal feedback can be deemed as a constructive way of improving students' performance. 
In the following section, several types of verbal feedback have been discussed.

\subsection{Positive and negative feedback}

Feedback can be identified as positive or negative. Positive feedback confirms a correct response from the learner. In contrast, negative feedback refers to oral feedback, which aims at error correction [3]. Examples of teacher's positive feedback include 'good,' 'yes', and 'well done', which are phases that might lead to rewards and acknowledgments. However, these forms may not always signal that the student's response is correct, as they could also act as a preface to subsequent correction or modification of students' responses. Negative feedback, on the contrary, is a way to pinpoint the exact errors of the students, meaning direct correction and probably punishments. Many teachers have not had good role models themselves with regard to giving what types of feedback. They might feel much more comfortable staying in the realm of positive feedback rather than addressing areas that students need to work on. There is no claim indicating which types are the best because the appliance of these two types of feedback depends on the students' personalities and the types of tasks.

\subsubsection{Student's Self-esteem}

Self-esteem is considered a motivational trait because it influences how individuals perceive and respond to negative feedback (e.g., Brocknding to the self-enhancement theory) [4]. That means people are more likely to accept appraisal performance evaluation, low self-esteem individuals should have a weaker preference for negative feedback than high self-esteem individuals, because they have a stronger need for selfenhancement than their high self-esteem counterparts. Negative feedback does not address that need. Low selfesteem individuals will react more strongly to positive feedback than high self-esteem individuals because they will presumably experience the greatest selfenhancement due to the positive feedback. When experiencing negative feedback, low self-esteem people, in comparison with high self-esteem individuals, felt worse about themselves [5], experienced more negative affect [6, 7], and had lower feelings of self-worth [8]. In conclusion, the teacher should prioritize positive feedback in front of low self-esteem students.

\subsubsection{The types of tasks}

Applying Higgins' regulatory focus theory, we hypothesized that the effect of positive/negative feedback on motivation and performance is moderated by task type, including promotion task. It requires creativity and open-mindedness, and prevention task demands vigilance and attention to details, accuracy, and adherence to rules. In some cases, we expect that positive feedback, more than negative feedback, will contribute to the performance of tasks that require eagerness and creativity as it indicates that we are making progress and serve as a stimulus to push students. In contrast, negative feedback is essential for identifying errors or avoiding problems as it indicates to people when they are wrong and what they should avoid.

\subsection{Content and form feedback}

Form feedback consisted of underlining all grammar errors. Content feedback consists of general comments that were not texting specific such as cohesion and coherence. Zamel proposed that content feedback and form feedback should be kept separately to avoid confusing students about what they should attend at any particular stage of the process [9].

Transcript 1[10]:

$\mathrm{T}$ : The garden look (not clear) tidy up, yes, so is there.

Yes?

S: It was hard work but a lot of fun.

T: It was hard work but a lot of fun but.

Yes?

S: They are many butterflies here because they are attracted to the colorful flowers.

$\mathrm{T}$ : They are many butterflies here because they are attracted to the colorful flowers.

Which conjunctions?

S Because.

$\mathrm{T}$ : Because.

Ok, so let's look at page 54.

Transcript 2 [10]:

$\mathrm{T}$ : Ok, how the others?

Has anyone gone through such an experience?

So?

S: Teacher,

T: Ha? Flood, your house?

S: No.

T: No, then?

S: In our area.

T: Area? Yours, ok, ok, ok, worse or not?

S: Worse. 
T: Really worse? Right, so this kind of thing we even. aa. some of you gone through, some of you maybe you have heard from your friend or the newspaper or any documentary.

\section{Yes?}

S: Yes.

T: All right."

The two examples were found not only to focus on form but also content. An example of focusing on the form can be found in the first transcript. In this exchange, the teacher repeated the exact structure of the response given by the student. This pattern can be seen as confirming or accepting what the student has said and emphasizing linking words in the grammatical sense. However, in the second transcript, the repetitions focused on content. In this particular example, the topic discussed involved students' experiences of 'natural disasters. When the teacher repeated the students' responses, she sought clarification of what the students intended to say. For example, when she repeated the word 'area', she identified which area the student referred to. In addition to the repetition, the teacher would also 'prompt' students for more information. The prompts used here were short phrases, for example, 'then?', 'worse or not?', 'yours?' expand and further clarify her answer. Thus, this act can be an effective instructional tool to engage students in modifying their thinking and learning process. According to the text, the teacher applied two different types of feedback, focusing on a different aspect of knowledge. The first part concentrates on the grammatical function of linking work, and the second part aims at expending students' ideas and clarifying several concepts.

\section{HOW DO GESTURES HELP TEACHERS TO TEACH}

According to Cambridge Dictionary, the definition of gesture is "a movement of the hands, arms, or head, etc., to express an idea or feeling". It is well-known that gestures are great tools to assist teaching. Through different gestures, we can encourage students to learn and improve classroom teaching efficiency.

\subsection{Lexis}

According to Cambridge Dictionary, the definition of lexis is "all the words of a language", teachers' gestures play an important role in lexis teaching, albeit many gestures can be categorized in multiple types. An attempt was made to classify the many different types of gestures into certain categories. The following sections include examples of 2 lexical gestures.

\subsubsection{Metaphoric Gestures}

According to Gullberg, metaphoric gestures depict abstract entities or the vehicle of a metaphor [11]. For instance, the well-known 'conduit metaphor' of communication shows thought and ideas represented as objects that can be held in hand $[12,13]$. "As an example of one of the many metaphoric gestures observed, the instructor demonstrated the word crazy when she was explaining the spelling of ie, and ei." [14].

Transcript 3 [14]:

T: Aghhhh, it makes you crazy.

[RH and LH grab hair at the sides of her head]

\subsubsection{Reflexive Gesture}

As the teacher depicted her holiday, she lifted her left hand to imply herself and then put her hands on her chest to imply that it was her holiday. This is revelatory of the fact that it was self-disclosure, and she exhibited a reflexive gesture through saying "mine." It is significant to mention that she was also leaning onward while using her entire body to explain the language. In addition to gesture, body movement was also combined by the teacher into her lexical expositions.

Transcript 4 [14]:

$\mathrm{T}$ : mine

[LPO touches chest]

From the two examples, we can see that the gestures in lexical learning can improve classroom efficiency and promote students' understanding of lexis. These gestures can also let students learn the correct meaning of lexis subconsciously. To sum up, gestures of lexical learning can assist teaching to a certain extent.

\subsection{Grammar}

The gestures related to grammar consist of a significant part of gestures. These grammatical gestures are organized according to the categories of deictic gestures. A part of the dance is also contained.

\subsubsection{Deictic Gestures}

In the following case, the teacher explained to the pupils that while they were giving speeches about a holiday, the verbs used needed to be in the past tense. In the 125 following skeletons describing this case, the teacher pointed behind her and highlighted her arguments by taking backward a step at the same time as though shifting into the past. About her hands, her left hand was lifted by her specifically to point behind her with her thumb. In the following case, the teacher shifted from a place next to the table of the students to a 
place in the presence of the table of the students. In this case, and this part of the class, the teacher was mentioning simple past tense. This case illustrates the physicality (the quality of being physical rather than emotional or spiritual) of the pedagogic style she was in. This was used as a feature of her teaching typically.

Transcript 5 [14]:

T: Past.

[used LHF with the thumb to point behind her]

<stepped backward with the left foot and then right foot as she gestured with her hand>

\subsubsection{Dance}

In the following case, where the teacher explained the past tense, she appeared to be dancing since she bobbed her head and bent her knees as she pointed with her left hand for stress. All of this occurred as she said the word told. The lesson's point 133 was to give reasons for simple past tense's use. In the picture, the head of the teacher is bent down, and her knees are bent.

Transcript 6 [14]:

T: Repeat. Tell. What if it's past tense? Teacher what? Told us.

\section{[used LH index finger to point]}

<emphasized the word told while bending her knees and moving her head forward and down>

From the two examples, we can see that the gestures of grammatical learning can strengthen students' understandings of grammatical knowledge. These gestures can also guide students to correctly know about the grammar that they are learning. To sum up, gestures of grammatical learning can assist teaching to a certain extent.

\subsection{Pronunciation}

It is acknowledged that pronunciation should be taught by word expressions, sounds, intonation, syllabification, and relevant methods. However, gestures are of vital significance in pronunciation teaching as well.

\subsubsection{Metaphoric Gestures}

As in the following case, other cases of metaphoric gestures the teacher raised indicate sound's "length". To get through the gesture 142 above, the teacher reached both hands out ahead of her in an endeavor to point out vowel sounds' length of a metaphoric gesture.

Transcript 7 [14]:

T: it's long. [extends both arms forward to emphasize that these voiced vowel sounds have duration]

\subsubsection{Mouth Shape}

The instructor exhibited other gestures related to pronunciation to demonstrate to students their mouths' correct shape when saying certain sounds. In the following example, the instructor was discussing the difference between pronouncing long and short vowel sounds. She exhibited the following gesture to demonstrate mouth shape when producing a short vowel sound.

\section{Transcript 8 [14]:}

T: Your mouth is more short <.> this way.

$[\mathrm{RH}$ index finger and $\mathrm{LH}$ index finger touch the sides of the mouth, pointing up, and slide up and down rapidly seven times]

\section{Ship. Ship.}

$[\mathrm{RH}$ index finger and $\mathrm{LH}$ index finger touch the sides of the mouth, pointing up]

Sheep.

[RH index finger and $\mathrm{LH}$ index finger touch the sides of the mouth, pointing up, and slide outward, pulling the mouth into a smile]

From the two examples, we can see that the gestures of pronouncing learning can give students a vivid example of how to correctly pronounce. These gestures can also guide students to subconsciously imitate the teachers' gestures and, therefore, lead to the right pronunciation. To sum up, gestures of pronouncing learning can assist teaching to a certain extent.

\section{TEACHERS' OTHER CHARACTERISTICS}

People's first impression of others is clothing apart from their looks. In the same way, students see the same group of teachers in school every day. Then, based on the same appearance, when students see the teacher every day, their attention is often affected by the teacher's clothes.

\subsection{Dressing's importance}

Undeniably, different attire brings different impressions. Hoping to perfection, an institution can set an official dress code or even set guidelines appropriate for wearing for the classroom [15].

However, we see what we see nowadays seldom do education administration make a discipline to regulate teachers' dressing. Teachers are their own masters, 
which means they feel free to decide daily attire. Perhaps the best advice is for every teacher to "dress as you wish to be perceived," for that is how you will be treated [16]. This points out that teachers should think hard about their dressing before getting into school.

\subsection{Dressing style}

Which style a teacher should choose has been defined differently in various student groups. A study asked 100 college students to rate the formal, moderate, and informal clothing photos of ten teachers on a fivepoint scale. This research calculated the average scores obtained by male and female teachers wearing different styles of clothes. There is no doubt that the style of dressing will have a significant impact on teachers. Concluded from this report, the well-dressed professors/teachers are considered more organized, knowledgeable, and better prepared. In contrast, professors/teachers who wore informal clothing were seen as friendlier, flexible, sympathetic, fair, and enthusiastic by the students' judgment [17].

In addition, the normal phenomenon in society is that when people want to get closer to others, they should wear the same type of attire. In the same way, when a teacher wears an attire that students will wear in their spare time, which makes the teacher similar to that of a youngster, it can bring an intimate atmosphere to the classroom. However, the truth is the opposite. A rule of thumb for giving speeches holds that the speaker should dress "one cut above" the audience. Basing one's dress on students 'dress might not be the best idea, but dressing like peers who have earned the respect of students could prove to be a useful tactic [16]. Therefore, teachers should dress more decently can promote prestige. In that case, students become more modest and eager to learn.

\subsection{Teachers'gender}

Now, consider a situation. When students are informed that a new teacher will present, what is the first question that students will come up with" Normally, it is about the gender of the new teacher. So, students do care about the gender of the teachers.

Male and female teachers are different from each other while they interact with their students [4]. People know that whether it is physical or psychological, men and women are very different. Therefore, in terms of actions and teaching, male and female teachers will teach in a more suitable way for their gender. In other words, there is a great difference between the behavior of men and women teachers in the classrooms. Since the interaction patterns are gender-related, this genderbased phenomenon often has varying degrees of impact on the efficiency of classroom interaction and leads to different results.

\subsubsection{Ways of delivering a lecture}

During a course, the teacher needs to make an organized plan to go over the class schedule. Male and female teachers are different from each other while they interact with their students. The pedagogical ways will also change according to the gender of the teacher. Male teachers used many display questions, but female teachers asked more referential questions, which promoted more interactions between the students and the teacher [18].

Also, organizing activities to build up students' cooperative ability is a common pedagogical method. Teachers also utilize this method to improve the interest of the course. However, communication skills are normally more appropriately used in female teachers' courses. Female teachers were more interactive with their students [18]. Hence, female teachers pay a lot of attention to the interaction with students while male teachers are more focused on the academic stuff.

\subsubsection{Effects on students' grades}

Student performance can be regarded as a very important criterion for the efficiency of classroom interaction. Although the knowledge learned cannot be fully reflected in the exam, it has to be denied that the results are still within a range of thinking about whether parents approve of the teacher's teaching methods.

One study investigated the role of teacher gender in educational production. From this study, we can see whether teachers of different genders can affect students' academic performance. Having a female teacher improves both academic performance and noncognitive outcomes more for girls than boys [19].

In addition, Thomas Dee, associate professor of economics and visiting scholar at Stanford University in California, conducted a related study [20]. Dee found that students, especially girls, do better and get better academic scores under the guidance of female teachers.

\section{CONCLUSION}

Classroom interaction is a significant part in teaching, except common teaching methods, teachers' characteristics play a crucial role in classroom interaction as well. In this paper, we have discussed about three kinds of teachers' characteristics that impact classroom interactions, which including verbal feedback, body gestures, and some other factors. We found that verbal feedback can be effective instructional tools for students through impacting their self-esteem and giving various types of tasks. As a result, teachers need to notice their words during the pedagogical process. Gestures are essential body languages in teaching, teachers can imperceptibly influence students through gestures, so that students can learn certain 
knowledge unconsciously. And teachers' other characteristics like dressing and gender are also found effecting students' learning efficiency. We sincerely hope this paper can help teachers and researchers continue to dig deep into this area as well as enhance classroom interactions and master student's acceptance of teachers.

\section{REFERENCES}

[1] Ur, Penny. A course in language teaching: Practice and theory. Ernst Klett Sprachen, 1996.

[2] Lewis, Marilyn. Giving feedback in language classes. SEAMEO Regional Language Centre, 2002.

[3] Lyster, Roy, and Leila Ranta. "Corrective feedback and learner uptake: Negotiation of form in communicative classrooms." Studies in second language acquisition (1997): 37-66.

[4] McCauley, Clark R., Lee J. Jussim, and Yueh-Ting Lee. Stereotype accuracy: Toward appreciating group differences. American Psychological Association, 1995.

[5] Bernichon, Tiffiny, Kathleen E. Cook, and Jonathon D. Brown. "Seeking self-evaulative feedback: The interactive role of global self-esteem and specific self-views." Journal of personality and social psychology 84.1 (2003): 194.

[6] Kernis M H, Brockner J, Frankel B S. Self-esteem and reactions to failure: The mediating role of overgeneralization $[\mathrm{J}]$. Journal of personality and social psychology, 1989, 57(4): 707.

[7] Moreland, Richard L., and Paul D. Sweeney. "Selfexpectancies and reactions to evaluations of personal performance." Journal of Personality 52.2 (1984): 156-176.

[8] Brown, Jonathon D., and Keith A. Dutton. "The thrill of victory, the complexity of defeat: Selfesteem and people's emotional reactions to success and failure." Journal of personality and social psychology 68.4 (1995): 712.

[9] Zamel, Vivian. "Responding to student writing." TESOL quarterly 19.1 (1985): 79-101.

[10] Hyland, Fiona, and Ken Hyland. "Sugaring the pill: Praise and criticism in written feedback." Journal of second language writing 10.3 (2001): 185-212.

[11] Gullberg, Marianne. Gesture as a communication strategy in second language discourse: A study of learners of French and Swedish. Vol. 35. Lund University, 1998.
[12] Lakoff, George, and Mark Johnson. "The metaphorical structure of the human conceptual system." Cognitive science 4.2 (1980): 195-208.

[13] Reddy, Michael. "The conduit metaphor." Metaphor and thought 2 (1979): 285 324.

[14] Hudson, Natalie. "Teacher gesture in a postsecondary English as a second language classroom: A sociocultural approach." (2011).

[15] Kashem, Mohammad Abul. "The Effect of Teachers' Dress on Students' Attitude and Students' Learning: Higher Education View." Education Research International, Hindawi, 26 Dec. 2019.

[16] Grubaugh, Steve, and Richard Houston. "Establishing a Classroom Environment That Promotes Interaction and Improved Student Behavior." The Clearing House: A Journal of Educational Strategies, Issues and Ideas, vol. 63, no. 8, 1990, pp. 377.

[17] Steven A., Rollman. "Some Effects of Teachers' Styles of Dress.” ERIC, 31 Mar. 1980.

[18] Rashidi, Nasser, and Sahar Naderi. "The effect of gender on the patterns of classroom interaction." Education 2.3 (2012): 36.

[19] Gong, Jie, et al. "The Effect of Teacher Gender on Students' Academic and Noncognitive Outcomes." SSRN, 30 Sept. 2016.

[20] Dee, Thomas S. "Teachers and the gender gaps in student achievement." Journal of Human resources 42.3 (2007): 528-554. 